\title{
Hepsin inhibits the cell growth of endometrial cancer
}

\author{
KEIICHIRO NAKAMURA ${ }^{1}$, NORIO TAKAMOTO ${ }^{1}$, FERNANDO ABARZUA $^{2}$, ATSUSHI HONGO $^{1}$, \\ JUNICHI KODAMA $^{1}$, YASUTOMO NASU ${ }^{2}$, HIROMI KUMON ${ }^{2}$ and YUJI HIRAMATSU ${ }^{1}$ \\ ${ }^{1}$ Department of Obstetrics and Gynecology, ${ }^{2}$ Department of Urology, Okayama University \\ Graduate School of Medicine, Dentistry and Pharmaceutical Sciences, Okayama, Japan
}

Received March 21, 2008; Accepted May 19, 2008

DOI: $10.3892 /$ ijmm_00000035

\begin{abstract}
Currently, several therapeutic approaches including surgery, chemotherapy, and radiation therapy are available for the treatment of endometrial cancer. However, endometrial cancer cells may survive, resulting in relapse of the disease, and ultimately causing demise of the patient. Hepsin is a cell surface-expressed chymotrypsin-like serine protease and a member of the family of type II transmembrane serine proteases. To date, little is known about its precise mechanisms of action. We investigated the biological functions and effects in vitro and in vivo of Hepsin, using endometrial cancer cell lines transfected with Hepsin. In stably transfected Ishikawa/Hepsin cell lines (Hepsin-10 and -12), we observed a significant inhibitory effect on cell growth in a monolayer culture system and in anchorage-independent cell growth in soft agar in vitro. Furthermore, in a xenograft model, growth inhibitory effects were observed when compared with the effects of mock-transfected cells used as a control. Overall, Hepsin showed potential inhibitory effects mediated by the induction of 14-3-3 $\sigma$ expression which leads to both cell cycle arrest at the $G_{2} / M$ phase through cyclin $B$ and cyclin $A$ and the p53-dependent pathway activated by increasing the level of Bak and reducing the level of Bcl-2 and Bcl-xL.
\end{abstract}

\section{Introduction}

Endometrial cancer is one of the most common female pelvic malignancies and its incidence has recently increased (1). Due to poor prognoses of endometrial cancer, studies have been carried out to develop a more effective treatment. Along with surgical and chemotherapeutic regimens, gene therapy has emerged as one of the leading contenders in the treatment armamentarium.

Serine proteases are one of the largest and most conserved proteolytic multigene families. Hepsin is a cell surface-

Correspondence to: Dr Keiichiro Nakamura, Department of Obstetrics and Gynecology, Okayama University Graduate School of Medicine, Dentistry and Pharmaceutical Sciences, 2-5-1 Shikatacho, Okayama 700-8558, Japan

E-mail: k-nakamu@cc.okayama-u.ac.jp

Key words: Hepsin, endometrial cancer, cell cycle expressed chymotrypsin-like serine protease and a member of the family of type II transmembrane serine proteases (2). Previous studies demonstrated that Hepsin is active during the $\mathrm{G}_{2}-\mathrm{M}$ phase of the cell cycle, and also found an increase in the cell population undergoing apoptosis in LNCaP and PC-3 prostate cancer cells (3). Studies also showed inhibitory effects on cell growth in a monolayer culture, anchorageindependent cell growth in soft agar in vitro, and tumorigenicity in vivo through the p53-dependent pathway in BG-1 ovarian cancer cell lines transfected with Hepsin (4). However, little is known about its mechanisms of action.

p53 is a transcription factor that activates genes involved in growth arrest, apoptosis, DNA repair and angiogenesis (5). The apoptotic cell death and cell proliferation in stressed conditions are regulated at cell cycle checkpoints by

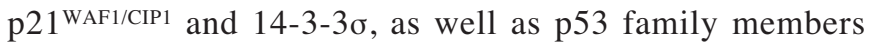
which are responsible for DNA damage (6).

DNA damage checkpoints operate throughout the cell cycle to maintain genetic integrity. DNA damage checkpoints delay cell cycle progression by the inhibition of the cyclindependent kinase (Cdk)-cyclin complexes. Cyclin-Cdk complexes are key regulators of the cell cycle: cyclin DCdk 4/6 for $G_{1}$ progression, cyclin E-Cdk 2 for the $G_{1}-S$ transition, cyclin A-Cdk 2 for $\mathrm{S}$ phase progression, and cyclin A/B-Cdc- 2 for $\mathrm{G}_{2} / \mathrm{M}$ phase (7). Damaged cells maintain a $4 \mathrm{~N}$ DNA content and a high level of cyclin B. Damaged cells sustained in the $G_{2}$ state contain a 4 N DNA content, with stabilized cyclin A and cyclin B binding to Thr14/Tyr15phosphorylated Cdc-2 (8).

A number of pro-apoptotic genes such as Bax (9) and Bak (10) are direct p53 target genes whose expression levels are up-regulated by p53. p53 is also involved in down-regulation of the anti-apoptotic genes Bcl-2 (11) and Bcl-xL (12). Functions of the p53-dependent pathway in cell cycle arrest and DNA damage repair are thought to prevent replication of damaged DNA and to protect cells from damage-induced apoptosis.

The purpose of the current study was to explore the role of Hepsin in endometrial cancer biology. Our results indicate that Hepsin overexpression inhibits the cell growth of endometrial cancer in vitro and in vivo.

\section{Materials and methods}

Cell culture and media. The Ishikawa, HEC-1A, EN cancer cell lines were derived from human endometrial carcinomas 
as described (13-15). Ishikawa cells were kindly provided by Dr M. Nishida (Kasumigaura National Hospital, Ibaraki, Japan); HEC-1A cells were provided by Dr H. Kuramoto (Kitasato University, Shizuoko, Japan); and EN cells were provided by Dr H. Nishi (Tokyo Medical University, Tokyo, Japan). These endometrial cancer cells were maintained in Dulbecco's modified Eagle's medium (DMEM) without phenol red (Life Technologies, Grand Island, NY), supplemented with $10 \%$ charcoal-stripped fetal bovine serum (FBS) to eliminate estrogenic effects. The LNCaP cell line was derived from a human prostate carcinoma. Prostate cancer cells were maintained in RPMI-1640 (Life Technologies, Inc., Rockville, MD) with $10 \%$ FBS. Cells were maintained at $37^{\circ} \mathrm{C}$ in an atmosphere of $5 \% \mathrm{CO}_{2}$ in air.

Western blot analysis. Cell lysates were collected and estimated using a Protein Assay system (Bio-Rad, Hercules, CA) according to the manufacturer's protocol. Proteins from each cell line were subjected to SDS-PAGE and were transferred onto a nitrocellulose membrane. Polyclonal and monoclonal antibodies used for immunoblotting were as follows: Hepsin (Cayman Chemical, Ann Arbor, MI), p53, 14-3-3o, Bak, Bax, Bcl-xL, Bcl-2 (Santa Cruz Biotechnology, Santa Cruz, CA), Cdc-2, cyclin B, cyclin A (BD Biosciences, Franklin Lakes, NJ), p63, p73 (Oncogene Research Products, Darmstadt, Germany), caspase- 3 and $\beta$-actin (Sigma Chemical, St. Louis, MO). The working dilution of all of these primary antibodies was 1:1000. Membranes were then incubated with appropriate secondary antibodies. Expression of antigenantibody complexes was detected with an enhanced chemiluminesence kit (Amersham Biosciences, Piscataway, $\mathrm{NJ}$ ).

Real-time PCR assay. Total RNA was extracted from cell lines using the acid guanidium-phenol-chloroform method (Isogen, Nippon Gene, Tokyo, Japan) according to the manufacturer's instructions. According to the protocol of the RNA PCR kit (Takara Co. Ltd., Kyoto, Japan), $2.5 \mu \mathrm{g}$ of total RNA was reverse-transcribed at $42^{\circ} \mathrm{C}$ for $30 \mathrm{~min}$ in $20 \mu 1$ of reaction solution containing $1 \mathrm{X}$ PCR buffer, $5 \mathrm{mM}$ $\mathrm{MgCl}_{2}, 1 \mathrm{mM}$ deoxynucleoside triphosphate, $2.5 \mu \mathrm{M}$ random 9 mers primer, 10 units of ribonuclease inhibitor and 5 units AMV reverse transcriptase. Real-time quantitative RT-PCR was performed using a rapid Lightcycler thermal cycler instrument (Roche Diagnostics, Light Cycler, Mannheim, Germany) under conditions recommended by the manufacturer. Primers for real-time PCR were 5'-CCAAGGACACCCTC CCTC-3' (Hepsin-F), 5'-AAGAGCATCCCTCATCAGG-3' (Hepsin-R), 5'-CAACTACATGGTTTACATGTTC-3' (GAPDH-F) and 5'-GCCAGTGGACTCCACGAC-3' (GAPDH-R), as described previously (16). The products were checked by melting point analysis and electrophoretic mobility. Standard curves for the calculation of the number of transcripts were plotted using plasmids containing the respective amplified fragment as an insert, and were corrected by using GAPDH as the reference gene.

Generation of transient and stable transfectants. For transient transfectants, a full-length Hepsin cDNA expression construct encoding Hepsin protein (cloned in Genestorm expression vector, pcDNA3.1/GS; Research Genetics) was transfected into the Ishikawa, EN and HEC-1A endometrial cancer cell lines using TransFast transfection reagent (Promega, Madison, WI) during a 48-h treatment. Hepsin stable transfectants in the Ishikawa cancer cell lines were generated using the TransFast transfection reagent. Zeocin $(0.6 \mathrm{mg} / \mathrm{ml})$ (Invitrogen, Carlsbad, CA)-resistant colonies were selected after 4 weeks. Two of these clones, designated Hepsin-10 and -12, were expanded for the experiments. Mock transfected cells served as the control.

MTS assay. In order to evaluate the cell proliferation effects of Hepsin, the MTS assay (Promega, Madison, WI) was performed. Cells were treated either with or without transient transfection with Hepsin treatment for $48 \mathrm{~h}$ and then MTS was added for $1 \mathrm{~h}$. The absorbance was read at a wavelength of $490 \mathrm{~nm}$ using an ELISA plate reader (Bio-Rad Systems, Hercules, CA).

Matrigel invasion assay. To investigate differences in invasive ability between cells expressing Hepsin, we used the BD BioCoat Matrigel Invasion Chamber (BD Bioscience, Bedford, MA). These chambers contain inserts with an $8-\mu \mathrm{m}$ pore-size membrane with a thin layer of Matrigel basement membrane matrix. The Matrigel matrix serves as a reconstituted basement membrane in vitro. Hepsin-10, Hepsin-12, and empty vectortransfected Ishikawa endometrial cancer cells were added in situ to $10 \mu \mathrm{g} / \mathrm{ml}$ of DiI (Invitrogen, Carlsbad, CA) in DMEM containing $10 \%$ FBS for $1 \mathrm{~h}$. Cells $\left(5 \times 10^{4}\right)$ of each genotype were added to the inserts, and $0.75 \mathrm{ml}$ of medium was added to the bottom of each well. After $48 \mathrm{~h}$ of incubation, membranes were removed from the inserts and mounted on slides, and the invading cells were counted using a microscope. Matrigel assays were performed in triplicate.

Cell growth in monolayer culture. Hepsin-10, Hepsin-12, and empty vector-transfected Ishikawa endometrial cancer cells were plated at a density of $2.5 \times 10^{4}$ cells/well in 6 -well plates containing DMEM without phenol red, supplemented with $10 \%$ charcoal-stripped FBS. Cell growth was assessed by counting the cell numbers by using a hemocytometer after 1 , 3,5 and 7 days of culture. All data points represent triplicate experiments.

Cell growth in soft agar. A cell suspension ( $1 \times 10^{4}$ cells/well) in $1 \mathrm{ml} 0.2 \%$ Noble agar with DMEM without phenol red supplemented with $10 \%$ charcoal-stripped FBS was overlaid onto a $35-\mathrm{mm}$ dish containing a $0.5 \%$ agar base. Colonies $>0.2 \mathrm{~mm}$ in diameter were counted on day 21 after culture. Soft agar assays were performed in triplicate.

Cell cycle analysis. Hepsin-10, Hepsin-12, and empty vectortransfected cancer cells were trypsinized, washed twice with phosphate-buffered saline (PBS), incubated with trypsin for $10 \mathrm{~min}$ at room temperature, incubated with trypsin inhibitor and RNase buffer for $10 \mathrm{~min}$ at room temperature, and stained with $200 \mu \mathrm{l}$ propidium iodide staining solution for $10 \mathrm{~min}$ in the dark at room temperature (Becton Dickinson, San Jose, CA). Finally, cells were analyzed with the FACS cytometer (Calibur ${ }^{\mathrm{TM}}$, Becton Dickinson). The cell cycle phase 
A

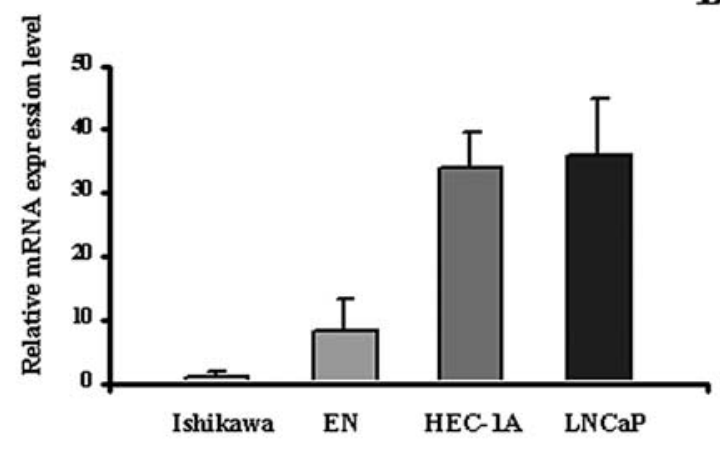

B

1. 2. 3. 4 .

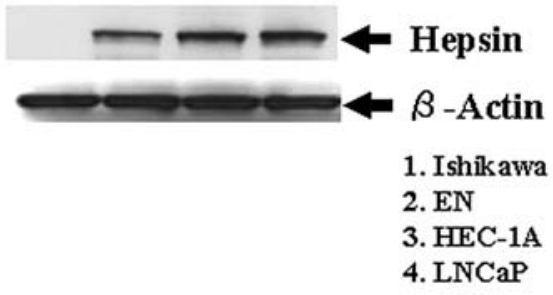

C

$\square$ Ishikawa Hepsin(-)

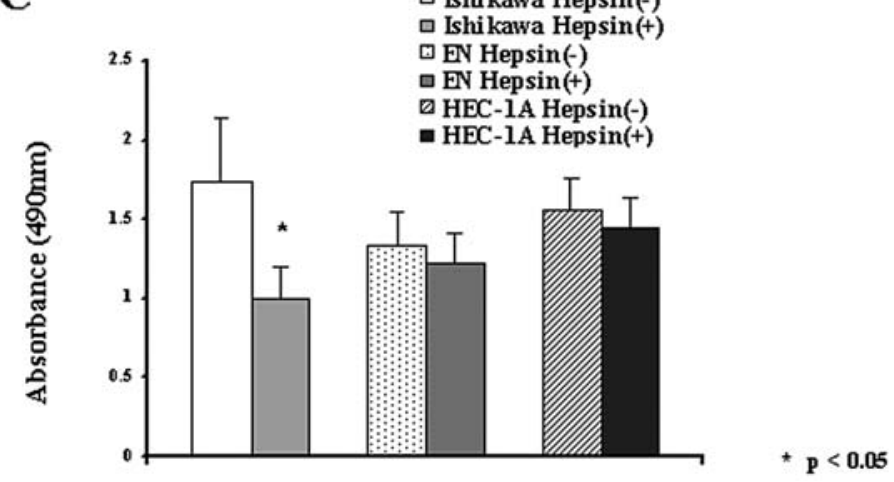

Figure 1. Evaluation of Hepsin expression in endometrial cancer cell lines. (A) Ishikawa, HEC-1A, EN and LNCaP cancer cell lines were analyzed for Hepsin mRNA expression using real-time quantitative PCR. GAPDH was used as an internal control. (B) Total cell lysates were prepared from established endometrial cancer cell lines (Ishikawa, HEC-1A, EN) and LNCaP prostate cancer cells, and were analyzed for Hepsin protein using Western blotting. B-actin antibody was used as a loading control. Evaluation of Hepsin expression in endometrial tissues. Immunohistochemical staining of Hepsin in normal endometrium, hyperplasia and endometrial cancer using anti-human Hepsin protein. (C) Effects on the cell proliferation in an MTS assay were analyzed for transient transfection of Hepsin in Ishikawa, EN and HEC-1A endometrial cancer cells. The absorbance was read at a wavelength of 490 nm using an ELISA plate reader. The assays were carried out for quadruplicate experiments.

distribution was determined using CellQuest software (Becton Dickinson).

Tumorigenesis in nude mice. Hepsin-12 and empty vectortransfected cancer cells were washed three times with Hank's solution and incubated with serum-free medium (SFM) at $37^{\circ} \mathrm{C}$ for $24 \mathrm{~h}$. Then cells were trypsinized and washed twice with PBS. As a xenograft, $2.5 \times 10^{7}$ cells suspended in $200 \mu 1$ of sterile PBS were injected s.c. above the hind leg of 5-week male BALB/c nude mice (Charles River Japan, Yokohama, Japan). The volume of the developed tumors $\left(\mathrm{cm}^{3}\right)$ was measured weekly as a spheroid from three-dimensional diameters. Each tumor volume represents the mean \pm SD from five different mice.

Statistical analysis. Statistical analyses were performed using the Mann-Whitney U-test for comparison with the control and one-factor ANOVA followed by Fisher's protected least significant difference test for all pairwise comparisons. The analyses were performed with the software package StatView version 5.0 (Abacus Concepts, Berkeley, CA). Differences were considered significant at $\mathrm{P}<0.05$.

\section{Results}

Evaluation of Hepsin expression in endometrial cancer cell lines. Extracellular and cell surface proteases play an important role in embryonic development and normal tissue homeostasis. Among these, serine proteases have been implicated in the degradation of the extracellular matrix and in the modulation of cell-substratum adhesion in tumor cells associated with metastasis. Levels of Hepsin mRNA and protein were determined using real-time PCR analysis and Western blotting in various endometrial cancer cell lines. As shown in Fig. 1A, Hepsin mRNA level was almost absent in the Ishikawa endometrial cancer cell line, low in the EN endometrial cancer cell line, and abundantly expressed in the HEC-1A endometrial cancer and LNCaP (our positive control) prostate cancer cell lines. Hepsin protein was detected by Western blotting as a single band in EN, HEC-1A and LNCaP cancer cell lines, but undetectable in the Ishikawa cancer cell line (Fig. 1B).

Transient transfection of Hepsin into cancer cell lines reduced cell growth in an MTS assay. We used MTS assays to examine the cell proliferation in Ishikawa, EN and HEC-1A endometrial cancer cell lines caused by Hepsin. The transient transfection of Hepsin into these three endometrial cancer cell lines caused reduced cell growth in an MTS assay, and the inhibitory effect was most prominent in the Ishikawa cancer cell line. For this reason, the Ishikawa endometrial cancer cell line was chosen for further experiments (Fig. 1C).

Generation of Hepsin-10 and -12 cells. To examine the functional role of Hepsin, stable cell lines which over- 
A
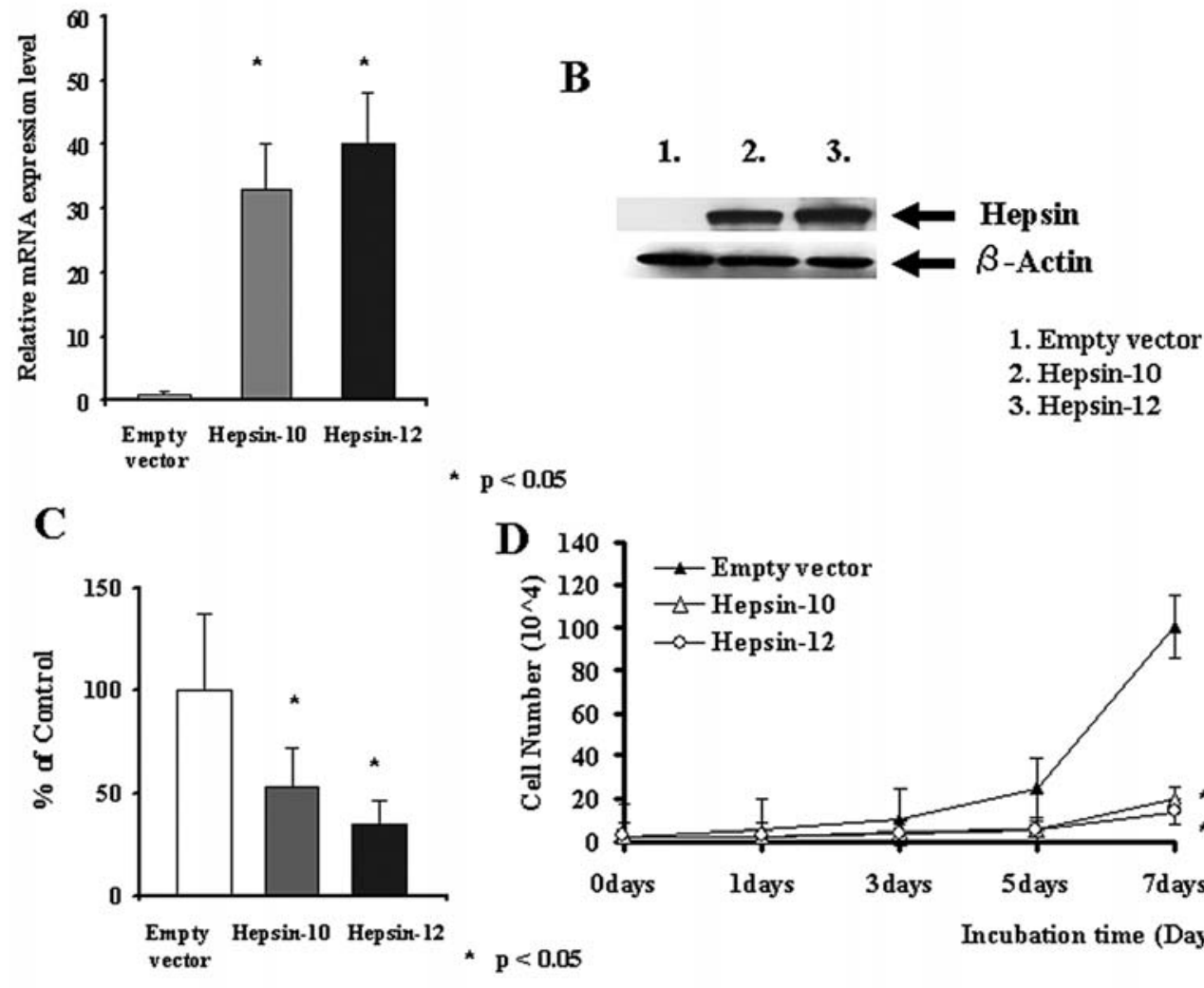

D 140

$\mathbf{E}$

Empty vector

$\star \mathrm{p}<0.05$
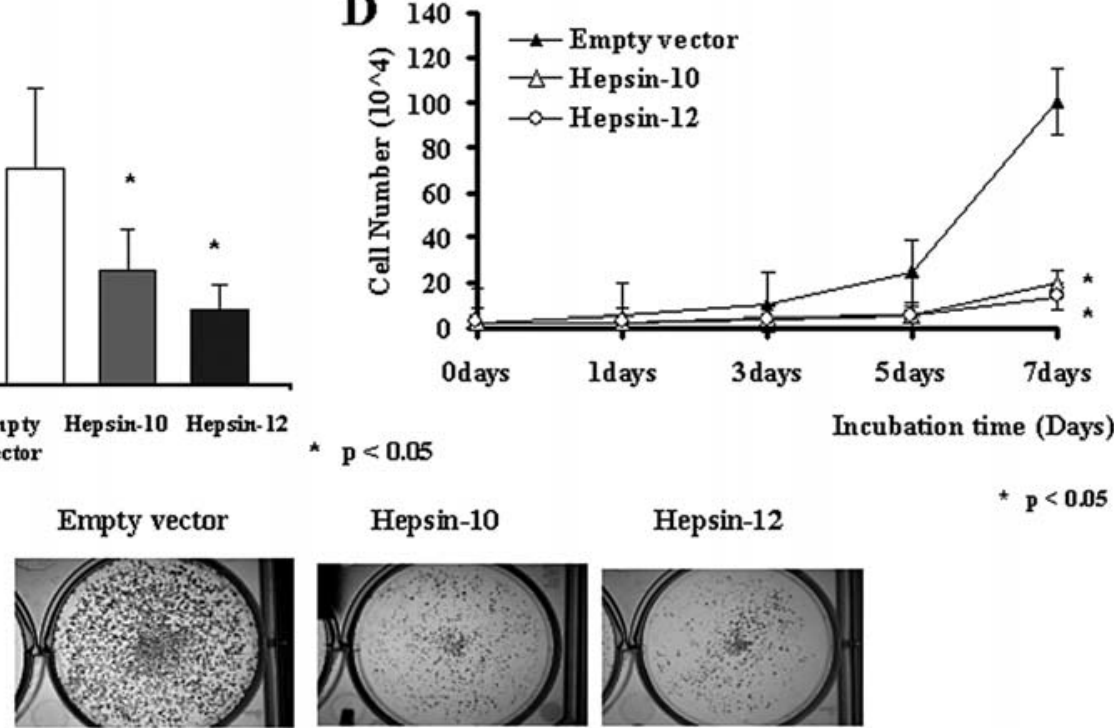

Hepsin-10

Hepsin-12

${ }^{*} \mathrm{p}<0.05$
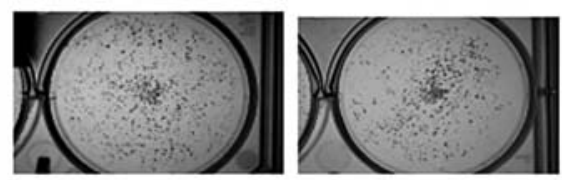

F Colony formation on soft agar of Hepsin transfectants

and empty vector-transfected Ishik awa endometrial cancer cells

\begin{tabular}{lcc}
\hline Cells & $\begin{array}{c}\text { Colonies/dish } \\
(\text { mean/SD) }\end{array}$ & Inhibitory effect (\%) \\
\hline Empty Vector & $51.5 \pm 3.8$ & 0 \\
Hepsin-10 & $7.0 \pm 1.1$ & $85.2^{* * *}$ \\
Hepsin-12 & $4.5 \pm 0.5$ & $91.5 * * *$ \\
\hline
\end{tabular}

** Numbersrepresent data from triplicate experiments

${ }^{\star \star \star} \mathbf{p}<0.01$

Figure 2. Hepsin was stably transfected into the Ishikawa cancer cell line using a TransFast transfection reagent. Zeocin (0.6 mg/ml)-resistant colonies were selected after 4 weeks. Cells derived from the individual colonies after transfection and drug selections were obtained by cloning cylinders and were then further expanded. (A) Hepsin-10 and-12 cells and empty vector-transfected Ishikawa cells were analyzed for Hepsin expression using real-time quantitative PCR. GAPDH was used as a loading control. (B) Total cell lysates were prepared from Hepsin-10 and -12 cells, and from empty vector-transfected Ishikawa cells, and were analyzed for Hepsin protein by Western blotting. B-actin antibody was used as a control on the same blot. (C) Matrigel invasion assay of Hepsin-10 and -12 cells and empty vector-transfected Ishikawa cells. Cells were plated at a density of $5 \times 10^{4}$ cells/well in 24 -well plates and were incubated for $48 \mathrm{~h}$ in DMEM supplemented with 5\% FBS. Following incubation, membranes were removed from the insert and mounted on slides, and the invading cells were counted under a microscope. Matrigel assays were performed in triplicate. (D) Monolayer growth of Hepsin-10 and -12 cells and empty vectortransfected Ishikawa cells. Cells were plated at a density of $2.5 \times 10^{4}$ cells/well in 6-well plates, and were incubated for 7 days in DMEM supplemented with $10 \%$ FBS. The number of cells was determined after an additional 1, 3, 5 and 7 days. Numbers represent data from triplicate experiments. (E) Hepsin-10 and -12 cells and empty vector-transfected Ishikawa cells were stained with crystal violet after fixation in $2 \%$ buffered formaldehyde at day 7 . (F) Colony formation on soft agar of Hepsin-10 and -12 cells, and empty vector-transfected Ishikawa cells. Numbers represent data from triplicate experiments.

expressed Hepsin were generated as described in Materials and methods. After the selection, both mRNA and protein levels of Hepsin were highly expressed in the Hepsin-10 and -12 cancer cells as expected (Fig. 2A and B).
Matrigel invasion of Hepsin-10 and -12 cells. We assessed motility and invasiveness of cells overexpressing Hepsin by using a BioCoat Matrigel Invasion Chamber. The Matrigel matrix serves as a reconstituted basement membrane in vitro, 
A

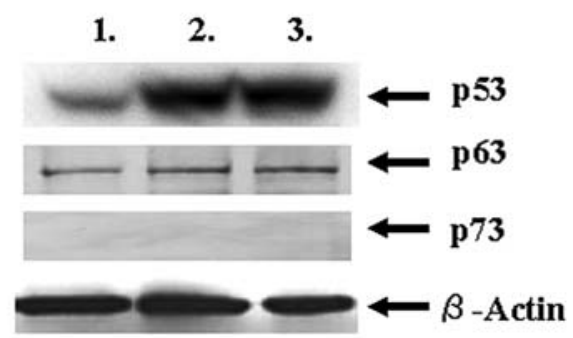

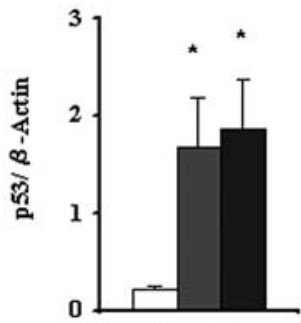

1. 2. 3 .

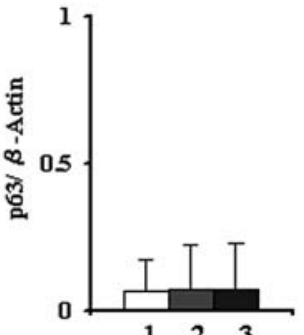

1. 2. 3 .

\section{B}

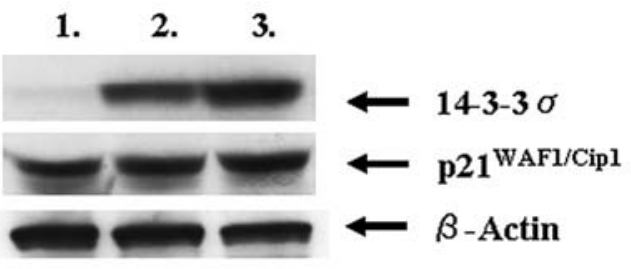

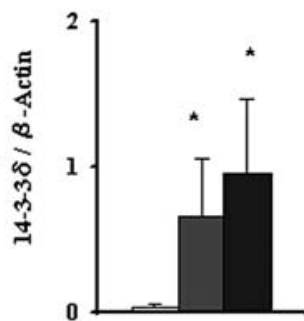

1. 2. 3

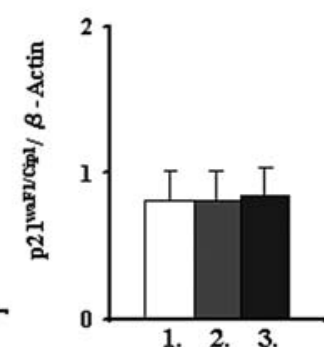

1. Empty Vector
2. Hepsin-10
3. Hepsin-12 * $\mathrm{p}<\mathbf{0 . 0 5}$

Figure 3. Effects on the p53 family pathway in stably Hepsin-transfected cells. (A) Total cell lysates were prepared from Hepsin-10, -12, and an empty vectortransfected Ishikawa cancer cells, and then cells were analyzed for p53, p63 and p73 expression by Western blotting. B-actin antibody was used as a loading control in the same blot. As a loading control, $\beta$-actin protein levels were also examined using the anti- $\beta$-actin antibody. The results represent the mean \pm SD of triplicate independent experiments $\left({ }^{*} \mathrm{P}<0.05\right)$. (B) Hepsin-10 and -12 cells and empty vector-transfected Ishikawa cells were analyzed for $14-3-3 \sigma$ and $\mathrm{p} 21^{\mathrm{WAF} 1 / \mathrm{Cip} 1}$ expression by Western blotting. $\beta$-actin antibody was used as a loading control in the same blot. As a loading control, $\beta$-actin protein levels were also examined using anti- $\beta$-actin antibody. The results represent the mean $\pm \mathrm{SD}$ of triplicate independent experiments $\left({ }^{*} \mathrm{P}<0.05\right)$.

and invasive cells are able to invade through the Matrigel matrix and the $8-\mu \mathrm{m}$ membrane pores. Cells were plated on the upper surface of the membrane, and after $48 \mathrm{~h}$, cells on the bottom side of the membrane were stained and counted (Fig. 2C). Hepsin-10 and -12 cells had significantly lower invasiveness through the Matrigel compared with the control.

Inhibition of cell growth in a monolayer culture and inhibition of anchorage-independent cell growth in soft agar in vitro of Hepsin-10 and -12 cells. Effects of Hepsin expression on cell proliferation were analyzed using Hepsin10 and -12 cells. We found a significant inhibitory effect of Hepsin on cell growth in Hepsin-10 and -12 cells $(\sim 70 \%$ inhibition $)(\mathrm{p}<0.05)$ compared to the empty vector-transfected Ishikawa cells as a control (Fig. 2D and E). Therefore, the inhibitory effects on colony formation in Hepsin-transfected cells were $\sim 90 \%$. Furthermore, in Hepsin-10 and -12 cells, the number of colonies in the colony formation assay was significantly reduced as compare with that in the control $(\mathrm{P}<0.01)$ (Fig. 2F).

Increased expression of p53 by Hepsin-10 and -12 cells. The targets of p53-regulated genes or p53-interacting proteins have provided critical information for understanding the biochemical and biological functions of the p53 tumor suppressor gene. Depending on cellular contexts, p53 activation can cause cell cycle arrest or apoptosis, contributing to tumor suppression. Previously, two genes encoding similar proteins to p53 have been identified, namely p63 and p73 (17-19). They act mostly as regulators in programmed cell death, embryonic development and cell differentiation (20). To determine whether expression of members of the p53 family (p53, p63, p73) of tumor suppressor genes correlates with Hepsin expression in endometrial cancer cells, the expression levels of p53, p63 and p73 protein were analyzed in Hepsin10 and -12 cells. Western blot analysis revealed an increased expression of p53 in both Hepsin-10 and -12 cells as compared to control cells. However, no significant changes in p63 expression were observed in Hepsin-10 and -12 cells (Fig. 3A).

Increased expression of 14-3-3o by Hepsin-10 and -12 cells. Having observed the up-regulation of p53 by Hepsin overexpression, we investigated the possibility that downstream of p53 might be altered in these cells. The p53 protein is a transcriptional activator of several genes, including the

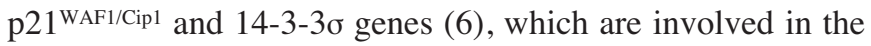
regulation of cell cycle progression. Therefore, we analyzed 14-3-3 $\sigma$ and $\mathrm{p} 21^{\mathrm{WAF} / \mathrm{Cip} 1}$ protein expression in Hepsin-10 and -12 cells. Western blot analysis revealed that expression of 
$\mathbf{A}$
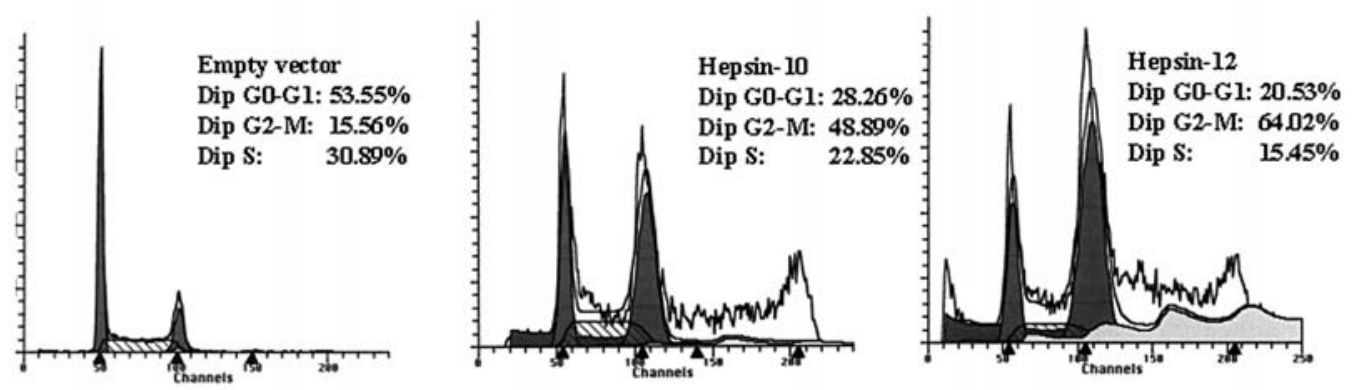

B

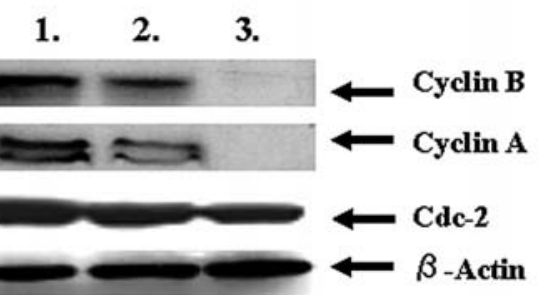

1. Empty vector

2. Hepsin-10

3. Hepsin-12
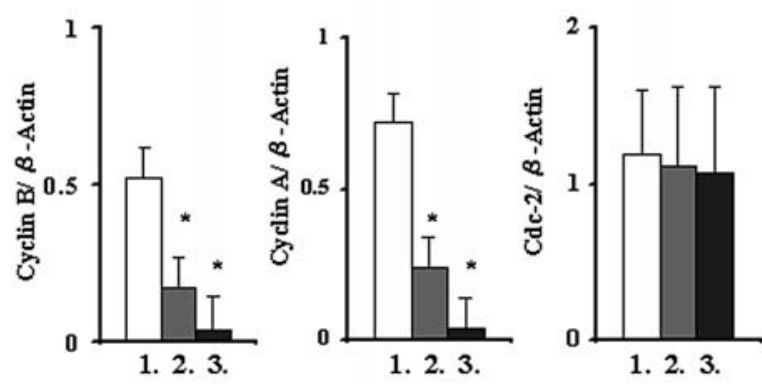

2. Hepsin-10

3. Hepsin-12

Figure 4. Effects on the cell cycle in stably Hepsin-transfected cells. (A) Hepsin-10, -12 cells and empty vector-transfected Ishikawa cells were analyzed by a cell cycle assay. Representative cell cycle profiles, measured by propidium iodide (PI) staining with percentages of cells in the $G_{0}-G_{1}, S, G_{2}-M$ phases, are shown. (B) Total cell lysates were prepared from Hepsin-10, -12, and empty vector-transfected Ishikawa cancer cells, and then cells were analyzed for cyclin B, cyclin A, Cdc-2 expression by Western blotting. B-actin antibody was used as a loading control in the same blot. As a loading control, B-actin protein levels were also examined using anti- $\beta$-actin antibody. The results represent the mean $\pm \mathrm{SD}$ of triplicate independent experiments $\left({ }^{*} \mathrm{P}<0.05\right)$.

14-3-3 $\sigma$ was increased in Hepsin-10 and -12 cells as compared with the control. However, no significant changes in p2 $1^{\text {WAF/Cip } 1}$ expression were observed in Hepsin-10 and -12 cells (Fig. 3B).

Accumulation of Hepsin-10 and -12 cells in the $G_{2} / M$ phase of the cell cycle. To investigate the mechanisms involved in the reduction of cell proliferation in Hepsin-transfected cells, the cell cycle profile of Hepsin-10, Hepsin-12, and empty vectortransfected cells was investigated. The cell cycle profile of the control was as follows: $\mathrm{G}_{0}-\mathrm{G}_{1}$ phase, $53.55 \% ; \mathrm{G}_{2}-\mathrm{M}$ phase, 15.56\%; and $\mathrm{S}$ phase, 30.89\%. In Hepsin-10 cells, 28.26, 48.89 and $22.85 \%$ of cells were in the $G_{0}-G_{1}, G_{2}-M$ and $S$ phases, respectively. In Hepsin-12 cells, $20.53 \%$ of cells were in the $\mathrm{G}_{0}-\mathrm{G}_{1}$ phase, while $64.02 \%$ of cells were in the $\mathrm{G}_{2}-\mathrm{M}$ phase and $15.45 \%$ of cells were in the $\mathrm{S}$ phase. Thus, cell cycle arrest was mainly observed at $\mathrm{G}_{2}-\mathrm{M}$ in Hepsin-10 and -12 cells. These data indicate that Hepsin might act to cause cell cycle arrest at the $\mathrm{G}_{2}-\mathrm{M}$ phase, supporting the idea that Hepsin is inhibitory to cell growth. In addition to cell cycle of pre- $\mathrm{G}_{1}$ and aneuploid peak alteration, a significant proportion of cells were found to be apoptotic. The pre- $\mathrm{G}_{1}$ and aneuploidy in Hepsin-10 and -12 cells were significantly increased as compared to empty vector-transfected cells (Fig. 4A).
It is well known that the entry of cells into the $M$ phase is regulated by Cdc-2 kinase. Activation of Cdc-2 is a complex process that requires multiple steps. The DNA damage checkpoint prevents the activation of cyclin B, cyclin A and thereby prevents cells from entering potentially deleterious mitosis when their DNA is damaged (21). It has been reported that 14-3-3o sequesters Cdc-2/cyclin B complexes in the cytoplasm to cause $\mathrm{G}_{2}$ arrest in response to DNA damage $(22,23)$. To determine whether overexpression of Hepsin alters the expression of $\mathrm{Cdc}-2$, cyclin $\mathrm{B}$ and cyclin A complex in endometrial cancer cells, cyclin B, cyclin A, and Cdc-2 protein expression levels were analyzed in Hepsin-10 and -12 cells. As shown in Fig. 4B, expression of cyclin A and cyclin B was decreased in Hepsin-10 and Hepsin-12 cells as compared with the control. However, no significant changes in Cdc-2 expression were observed in Hepsin-10 and -12 cells. Thus, these results are consistent with the finding that Hepsin overexpression causes cell cycle arrest at the $\mathrm{G}_{2}-\mathrm{M}$ phase.

Activation of the p53-dependent pathway in Hepsin-10 and Hepsin-12 cells. In addition, we also investigated the effect of Hepsin on several apoptotic molecules such as antiapoptotic Bcl-2, Bcl-xL, and pro-apoptotic Bax and Bak, which are known to take part in the activation of the caspase pathway (24-28). As shown in Fig. 5, Bak was up-regulated, 


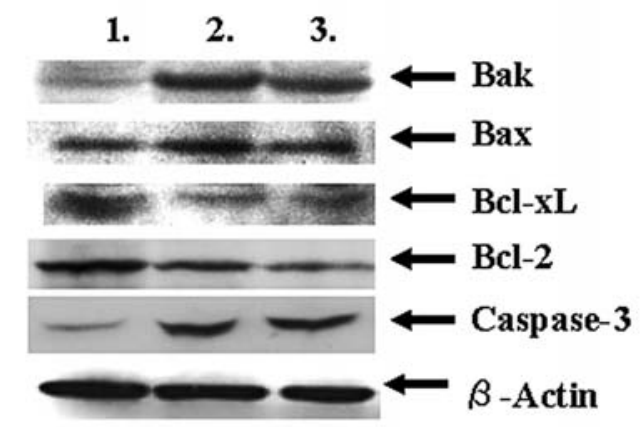

1. Empty vector
2. Hep sin-10
3. Hep sin-12
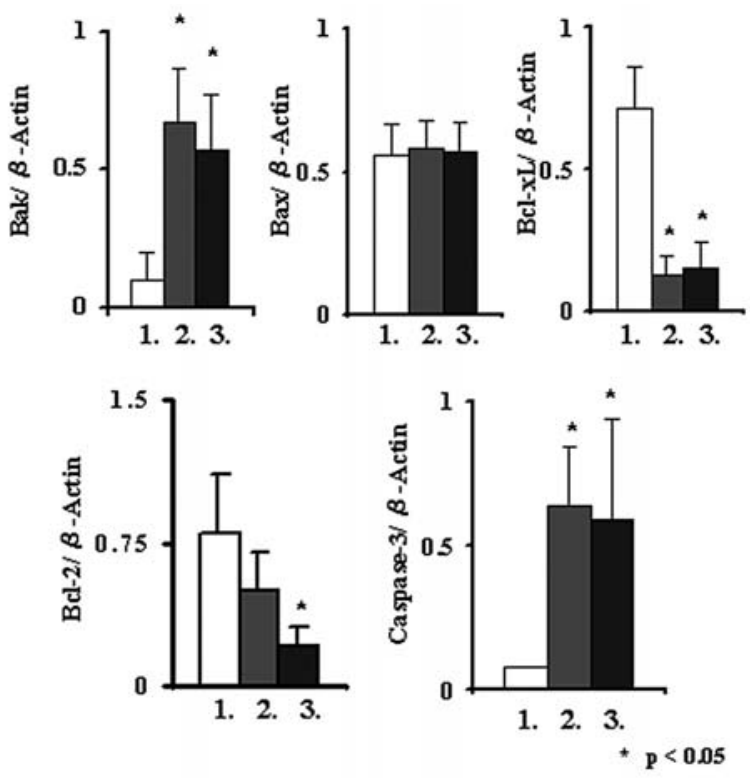

1. Empty vector
2. Hepsin-10
3. Hepsin-12

Figure 5. Effects on the expression of the p53-dependent apoptotic pathway in stably Hepsin-transfected cells. Hepsin-10 and -12 cells and empty vectortransfectants were analyzed for Bcl-2, Bcl-xL, Bax, Bak, and caspase-3 proteins using Western blotting. B-actin antibody was used as a loading control in the same blot. As a loading control, $\beta$-actin protein levels were also examined using anti- $\beta$-actin antibody. The results represent the mean \pm SD of triplicate independent experiments $\left({ }^{*} \mathrm{P}<0.05\right)$.

while Bcl-xL and Bcl-2 were down-regulated in Hepsin-10 and -12 cells. No significant change of Bax was observed in Hepsin-10 and -12 cells.

These results confirmed that a decrease in Bcl-2 and Bcl-xL, which are known as death antagonists due to their ability to suppress caspase-dependent pathways of apoptosis, play important roles in the p53-dependent pathway in Hepsinoverexpressing cells. To further investigate the specific apoptotic pathway regulated by Hepsin, we examined the effects of Hepsin on the caspase family by Western blotting. Analysis of protein levels in Hepsin-10 and -12 cells showed a significant increase in caspase-3 protein levels (Fig. 5).

Inhibition of tumor growth in vivo by overexpression of Hepsin. In a xenograft nude mouse model, we investigated the tumorigenic potential of Hepsin-12 cells. Tumor growth was followed for 5 weeks. Notably, there was a significant reduction in tumor growth in the Hepsin-12 group compared to the empty vector group. The extent of reduction in tumor volume compared to that of the control was $>95 \%(\mathrm{P}<0.01)$. Wet weight of tumors in mice inoculated with Hepsin-12 cells was significantly lower than control $(\mathrm{P}=0.0005)$ (Fig. 6A-C).

\section{Discussion}

The basement membrane is a specialized extracellular matrix structure that separates the epithelial and stromal cell compartments. To accomplish local invasion, tumor cells use extracellular and cell surface proteolytic enzymes to degrade the basement membrane proteins $(29,30)$. Serine proteases have been implicated in the degradation of the extracellular matrix and modulation of cell-substratum adhesion in tumor cells (30). Hepsin was found to be significantly overexpressed in cancer samples compared with matched normal tissues in prostate, ovary and kidney (31-33) cancer. To date, previous studies have shown that neutralizing antibodies against Hepsin inhibited cell growth and reduced the invasiveness of both DU145 prostate and CAOV-3 ovarian cancer cells (34). On the other hand, other studies have demonstrated that Hepsin overexpression caused $\mathrm{G}_{2}-\mathrm{M}$ arrest, and there was also an increase in the cell population undergoing apoptosis in LNCaP and PC-3 prostate cancer cells (3). Our previous study using ovarian cancer cell lines transfected with Hepsin showed inhibitory effects of Hepsin on cell growth in a monolayer culture, anchorage-independent cell growth in soft agar in vitro, and tumorigenicity in vivo through the $\mathrm{p} 53$-dependent apoptotic pathway in BG-1 ovarian cancer cells (4). It is still unknown what mechanisms might be involved. Therefore, we decided to study the effect of Hepsin overexpression in endometrial cancer.

It has been proposed that $\mathrm{G}_{2}-\mathrm{M}$ phase arrest caused by DNA-damaging agents or by stress stimuli, could provide an opportunity for DNA repair. One of the modes of nonapoptotic cell death after $\mathrm{G}_{2}-\mathrm{M}$ phase arrest has been described as 'mitotic death' or 'mitotic catastrophe' $(35,36)$. Mitotic death often occurs in $\mathrm{G}_{2}-\mathrm{M}$ phase-arrested cells after incomplete or defective mitosis (37). Therefore, DNA damage checkpoints delay cell cycle progression by inhibition of the Cdk-cyclin complexes. Cyclin-Cdk complexes are key regulators of the cell cycle: cyclin A/B-Cdc- 2 for $\mathrm{G}_{2} / \mathrm{M}$ phase (7). In this study, we examined the effects of Hepsin overexpression on cell cycle and the Cdk-cyclin complex, using 
$\mathbf{A}$

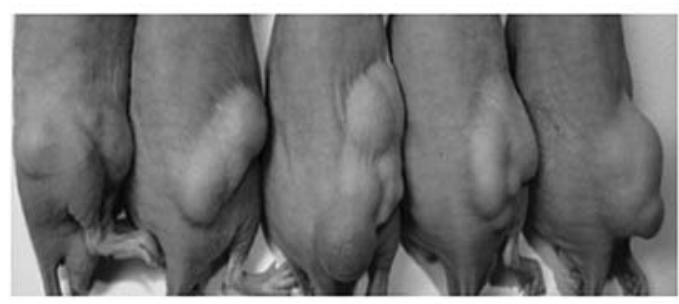

Empty vector

B

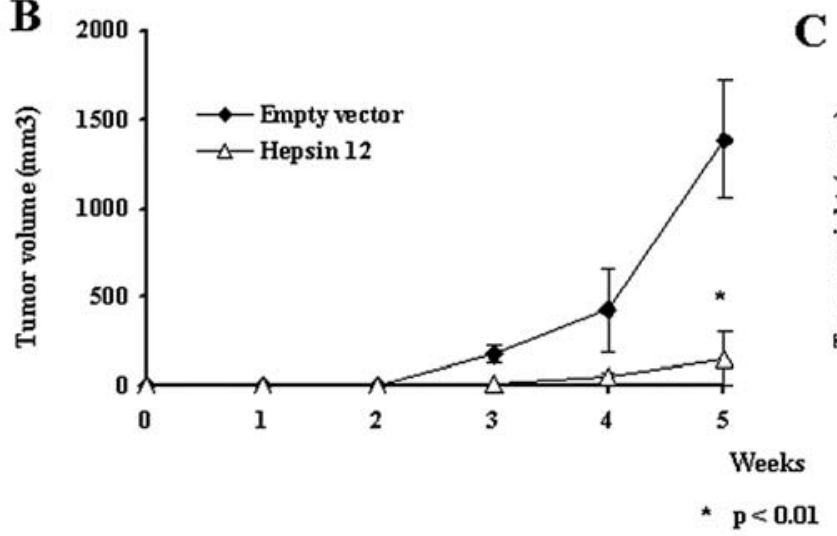

Hepsin-12

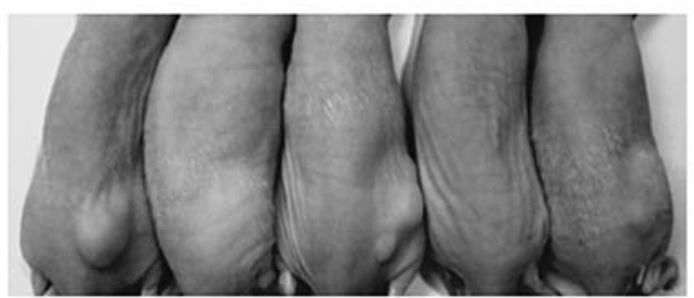

C

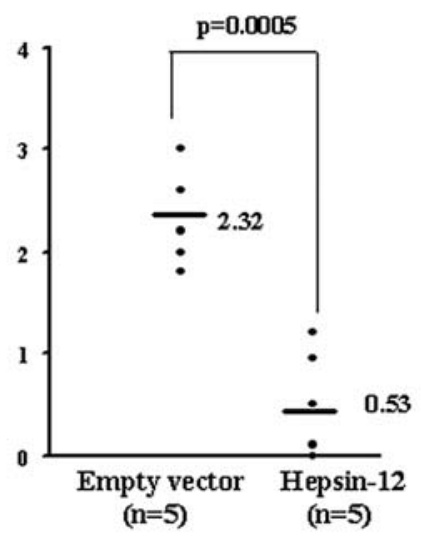

D

Hepsin $\uparrow \uparrow$

$\downarrow$

-143-3 $\sigma$ expression $\uparrow \uparrow$

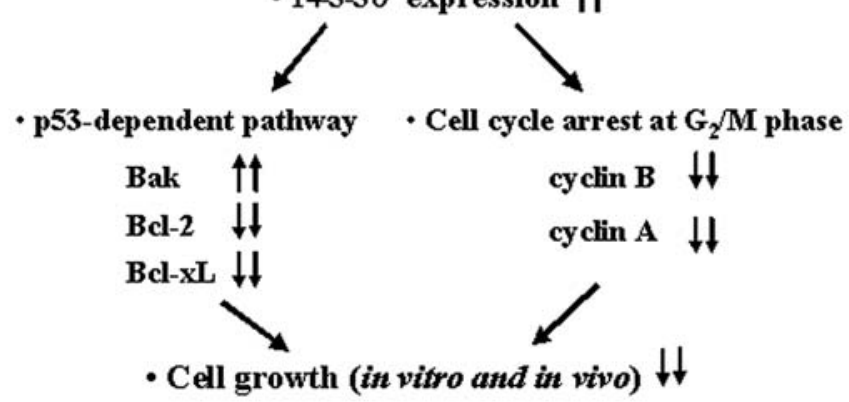

Figure 6. In vivo effects on tumor growth in stably Hepsin-transfected cells. (A) Appearance of tumors at the end of the observation period. (B) Volumes of established tumors were measured weekly as spheroids with three-dimensional diameters. Each point represents the mean \pm SD from 5 mice. Means for tumors \pm SD at specific observation times are shown. (C) Tumor weights 5 weeks after inoculation. All tumors were excised and weighted. Horizontal lines represent the mean results $(n=5)$. (D) Model of endometrial cancer cell line affected by Hepsin-transfection. Hepsin shows potential inhibitory effects

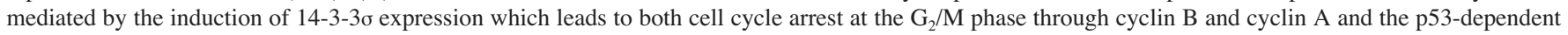
pathway through Bak, Bcl-2 and Bcl-xL in Ishikawa endometrial cancer cells.

the Ishikawa endometrial cancer cell line. Hepsin overexpression resulted in significant cell accumulation at the $\mathrm{G}_{2} / \mathrm{M}$ phase through cyclin B and cyclin A. Moreover, 14-3-3 $\sigma$ and p53 expression was activated by Hepsin overexpression. $14-3-3 \sigma$ is known to be induced by DNA damage and is required for a stable $G_{2}$ cell cycle arrest in epithelial cells expressing wild-type p53 $(38,39)$. Loss of $14-3-3 \sigma$ results in malignant transformation in vitro and supports tumor formation in vivo, which suggests that this gene has tumorsuppressive properties (40). Thus, it could be speculated, as shown in Fig. 6D that Hepsin shows potential inhibitory effects mediated by induction of 14-3-3 $\sigma$ expression which leads to both cell cycle arrest at the $\mathrm{G}_{2} / \mathrm{M}$ phase through cyclin $\mathrm{B}$ and cyclin $\mathrm{A}$ and the p53-dependent pathway in Ishikawa endometrial cancer. Similar effects of Hepsin overexpression were found in LNCaP and PC-3 prostate cancer cells (3).

In summary, our studies have revealed a critical role for Hepsin in the functional activity and effects in vitro and in vivo on endometrial cancer. We demonstrated that Hepsin induces cell cycle arrest at the $G_{2} / M$ phase through cyclin B and cyclin $\mathrm{A}$ and the p53-dependent pathway, and thus we propose that Hepsin is a possible tumor suppressor gene of endometrial cancer.

\section{Acknowledgements}

We are grateful to Dr M. Nishida for providing the Ishikawa cells; to Dr H. Kuramoto for providing the HEC-1A cells; to 
H. Nishi for providing the EN cells; and to the Center for Prostate Disease Research (Dr Johng S. Rhim) for providing the full-length Hepsin cDNA construct encoding Hepsin fusion proteins.

\section{References}

1. Jemal A, Tiwari RC, Murray T, Ghafoor A, Samuels A, Ward E, et al: Cancer statistics, 2004. CA Cancer J Clin 54: 8-29, 2004.

2. Leytus SP, Loeb KR, Hagen FS, Kurachi K and Davie EW: A novel trypsin-like serine protease (hepsin) with a putative transmembrane domain expressed by human liver and hepatoma cells. Biochemistry 27: 1067-1074, 1988.

3. Srikantan V, Valladares M, Rhim JS, Moul JW and Srivastava S: Hepsin inhibits cell growth/invasion in prostate cancer cells. Cancer Res 62: 6812-6816, 2002.

4. Nakamura K, Nasu Y, Hongo A, Matsuo T, Kodama J, et al: Hepsin shows inhibitory effects through apoptotic pathway on ovarian cancer cell lines. Int J Oncol 28: 393-398, 2006.

5. Vogelstein B, Lane D and Levine AJ: Surfing the p53 network. Nature 408: 307-310, 2000.

6. Golubnitschaja O, Moenkemann H, Kim K and Mozaffari MS: DNA damage and expression of checkpoint genes p21 (WAF1/ CIP1) and 14-3-3 sigma in taurine-deficient cardiomyocytes. Biochem Pharmacol 66: 511-517, 2003.

7. Yam CH, Fung TK and Poon RY: Cyclin A in cell cycle control and cancer. Cell Mol Life Sci 59: 1317-1326, 2002.

8. Chow JP, Siu WY, Fung TK, Chan WM, Lau A, Arooz T, et al: DNA damage during the spindle-assembly checkpoint degrades CDC25A, inhibits cyclin-CDC2 complexes, and reverses cells to interphase. Mol Biol Cell 14: 3989-4002, 2003.

9. Evans DL and Mansel RE: Molecular evolution and secondary structural conservation in the B-cell lymphoma leukemia 2 (bcl-2) family of proto-oncogene products. J Mol Evol 41: 775-783, 1995.

10. Krajewska M, Moss SF, Krajewski S, Song K, Holt PR and Reed JC: Elevated expression of Bcl-X and reduced Bak in primary colorectal adenocarcinomas. Cancer Res 56: 2422-2427, 1996.

11. Yamamoto K, Ichijo $\mathrm{H}$ and Korsmeyer SJ: BCL-2 is phosphorylated and inactivated by an ASK1/Jun N-terminal protein kinase pathway normally activated at $\mathrm{G}(2) / \mathrm{M}$. Mol Cell Biol 19: 8469-8478, 1999.

12. Basu A and Haldar S: Identification of a novel Bcl-xL phosphorylation site regulating the sensitivity of taxol- or 2methoxyestradiol-induced apoptosis. FEBS Lett 538: 41-47, 2003.

13. Nishida M, Kasahara K, Kaneko M, Iwasaki H and Hayashi K: Establishment of a new human endometrial adenocarcinoma cell line, Ishikawa cells, containing estrogen and progesterone receptors. Nippon Sanka Fujinka Gakkai Zasshi 37: 1103-1111, 1985.

14. Kuramoto H, Tamura S and Notake Y: Establishment of a cell line of human endometrial adenocarcinoma in vitro. Am J Obstet Gynecol 114: 1012-1019, 1972.

15. Isaka K, Nishi H, Sagawa Y, Nakada T, Osakabe Y, Serizawa H, et al: Establishment of a new human cell line (EN) with TP53 mutation derived from endometrial carcinoma. Cancer Genet Cytogenet 141: 20-25, 2003.

16. Ernst T, Hergenhahn M, Kenzelmann M, Cohen CD, Bonrouhi M, et al: Decrease and gain of gene expression are equally discriminatory markers for prostate carcinoma: a gene expression analysis on total and micro-dissected prostate tissue. Am J Pathol 160: 2169-2180, 2002.

17. Schmale $\mathrm{H}$ and Bamberger $\mathrm{C}$ : A novel protein with strong homology to the tumor suppressor p53. Oncogene 15: 1363-1367, 1997.

18. Jost CA, Marin MC and Kaelin WG: p73 is a simian [correction of human] p53-related protein that can induce apoptosis. Nature 389: 191-194, 1997.

19. Yang A, Kaghad M, Wang Y, Gillett E, Fleming MD, et al: p63, a p53 homolog at 3q27-29, encodes multiple products with transactivating, death-inducing, and dominant-negative activities. Mol Cell 2: 305-316, 1998.
20. Strano S, Rossi M, Fontemaggi G, Munarriz E, Soddu S, et al: From p63 to p53 across p73. FEBS Lett 490: 163-170, 2001.

21. Jin P, Hardy S and Morgan DO: Nuclear localization of cyclin B1 controls mitotic entry after DNA damage. J Cell Biol 141: 875-885, 1998.

22. Laronga C, Yang HY, Neal C and Lee MH: Association of the cyclin-dependent kinases and 14-3-3 sigma negatively regulates cell cycle progression. J Biol Chem 275: 23106-23112, 2000.

23. Chan TA, Hermeking H, Lengauer C, Kinzler KW and Vogelstein B: 14-3-3 sigma is required to prevent mitotic catastrophe after DNA damage. Nature 401: 616-620, 1999.

24. Oda E, Ohki R, Murasawa H, Nemoto J, Shibue T, et al: Noxa, a BH3-only member of the bcl-2 family and candidate mediator of p53-induced apoptosis. Science 288: 1053-1058, 2000.

25. Kondo S, Barna BP, Morimura T, Takeuchi J, Yuan J, et al: Interleukin-1 beta-converting enzyme mediates cisplatin-induced apoptosis in malignant glioma cells. Cancer Res 55: 6166-6171, 1995.

26. Henkels KM and Turchi JJ: Cisplatin-induced apoptosis proceeds by caspase-3-dependent and -independent pathways in cisplatinresistant and -sensitive human ovarian cancer cell lines. Cancer Res 59: 3077-3083, 1999.

27. Wu GS and Ding Z: Caspase 9 is required for p53-dependent apoptosis and chemosensitivity in a human ovarian cancer cell line. Oncogene 21: 1-8, 2002.

28. Troy CM, Stefanis L, Prochiantz A, Greene LA and Shelanski ML: The contrasting roles of ICE family proteases and interleukin-1 beta in apoptosis induced by trophic factor withdrawal and by copper/zinc superoxide dismutase down-regulation. Proc Natl Acad Sci USA 93: 5635-5640, 1996.

29. Chang C and Werb Z: The many faces of metalloproteases: Cell growth, invasion, angiogenesis and metastasis. Trends Cell Biol 11: $37-43,2001$

30. Del Rosso M, Fibbi G, Pucci M, D'Alessio S, Del Rosso A, Magnelli L and Chiarugi V: Multiple pathways of cell invasion are regulated by multiple families of serine proteases. Clin Exp Metastasis 19: 193-207, 2002.

31. Stamey TA, Warrington JA, Caldwell MC, Chen Z, Fan Z, Mahadevappa M, et al: Molecular genetic profiling of Gleason grade $4 / 5$ prostate cancers compared to benign prostatic hyperplasia. J Urol 166: 2171-2177, 2001.

32. Tanimoto H, Yan Y, Clarke J, Clarke J, Korourian S, Shigemasa K, et al: Hepsin, a cell surface serine protease identified in hepatoma cells, is expressed in ovarian cancer. Cancer Res 57: 2884-2887, 1997.

33. Zacharski LR, Ornstein DL, Memoli VA, Rousseau SM and Kisiel W: Expression of the factor VII activating protease, hepsin, in situ in renal cell carcinoma. Thromb Haemost 79: 876-877, 1998.

34. Xuan JA, Schneider D, Toy P, Lin R, Newton A, Zhu Y, et al: Antibodies neutralizing hepsin protease activity do not impact cell growth but inhibit invasion of prostate and ovarian tumor cells in culture. Cancer Res 66: 3611-3619, 2006.

35. King KL and Cidlowski JA: Cell cycle and apoptosis: common pathways to life and death. J Cell Biochem 58: 175-180, 1995.

36. Sleimam RJ and Stewart BW: Early caspases activation in leukemic cells subject to etoposide-induced $\mathrm{G}_{2}-\mathrm{M}$ arrest: evidence of commitment to apoptosis rather than mitotic death. Clin Cancer Res 6: 3756-3765, 2000.

37. Bracey TS, Williams AC and Paraskeva C: Inhibition of radiation-induced $\mathrm{G}_{2}$ delay potentiates cell death by apoptosis and/or induction of giant cells in colorectal tumor cells with disrupted p53 function. Clin Cancer Res 3: 1371-1378, 1997.

38. Maeda T, Chong MT, Espino RA, Chua PP, Cao JQ, et al: Role of p21 (Waf-1) in regulating the G1 and G2/M checkpoints in ultraviolet-irradiated keratinocytes. J Invest Dermatol 119: 513-521, 2002.

39. Hermeking H, Lengauer C, Polyak K, He TC, Zhang L, et al: 14-3-3 sigma is a p53-regulated inhibitor of $\mathrm{G} 2 / \mathrm{M}$ progression. Mol Cell 1: 3-11, 1997.

40. Akahira J, Sugihashi Y, Suzuki T, Ito K, Niikura H, et al: Decreased expression of 14-3-3 sigma is associated with advanced disease in human epithelial ovarian cancer: its correlation with aberrant DNA methylation. Clin Cancer Res 10: 2687-2693, 2004. 